\title{
Characterization of Upper Air Way Tract in Snoring and Non-Snoring Patients: A CT Based Study
}

\author{
Fathia Abd El Rahman Mohamed Alamin'1, Caroline Edward Ayad² \\ ${ }^{1}$ College of Medical Applied Science, Jazan University, Jazan, KSA \\ ${ }^{2}$ College of Medical Radiological Science, Sudan University of Science and Technology, Khartoum, Sudan \\ Email: carolinayad@yahoo.com
}

Received 30 June 2016; accepted 2 August 2016; published 5 August 2016

Copyright (C) 2016 by authors and Scientific Research Publishing Inc.

This work is licensed under the Creative Commons Attribution International License (CC BY).

http://creativecommons.org/licenses/by/4.0/

c. (i) Open Access

\begin{abstract}
Snoring is part of the spectrum of sleep disordered breathing. The patients with snoring should be evaluated for nasal airway obstruction. In this study, the upper air way tract was characterized in snoring patients and compared with none snoring using a quantify method for the corresponding anatomic upper air way (UA) parameters examined by Computerized Tomography (CT). Two hundred Asian patients undergoing CT scanning for head and neck were included and were divided into two groups (snoring group [ $n=127]$ and non-snoring group $[n=73]$ ) (mean age: $44.8 \pm 15.9$ years and $26.2 \pm 7.0$ ). Total 8 parameters were measured on sagital reconstructed CT images for each subject. The differences in neck circumference (NC), linear distance between mandibular plane and hyoid bone (Mp-H), upper airway length (UAL), the maximum thickness of the soft palate (SP max), soft palate length (PNS-U), linear distance between anterior and posterior nasal spine (ANS-PNS), retroglosal width (RS), retroplatal width (RP) between the snoring and non-snoring groups were compared statistically using independent sample t-test. Results showed that the NC, UAL, and SP max were significantly higher in snoring group; however RP was found to be significantly lower. Inferior positioning of hyoid bone gives longer measurement for MP-H. In snoring group UAL was found to be significantly different at $p \leq 0.000$ between the two genders. All the measured variables showed no significant differences in respect to age. UA CT quantitative features play an important role in the characterization of the anatomy and are compared between snoring patients and non-snoring subjects.
\end{abstract}

Keywords

Snoring, Upper Air Way Tract, Computerized Tomography

How to cite this paper: Alamin, F.A. El R.M. and Ayad, C.E. (2016) Characterization of Upper Air Way Tract in Snoring and Non-Snoring Patients: A CT Based Study. Open Journal of Radiology, 6, 181-190.

http://dx.doi.org/10.4236/ojrad.2016.63025 


\section{Introduction}

The upper airway (UA) is comprised of numerous cylindrical segments of different cross-sectional areas and of unequal length; and therefore, the UA acts as tubes of Venturi [1]. The passage of airflow through these airways should satisfy the equation of Bernoulli and the law of Poiseuille [1] but it moderately assures these laws, because of its particular anatomical and functional features. The UA has different segments characteristics which can be firm or collapsible depending on morphology and trophicity [2].

During normal sleep the tone of the pharyngeal airway dilator muscles, the genioglossus, levator palati, and palatopharyngeus is decreased with resultant partial upper airway collapse and narrowing of the lumen giving rise to turbulent flow [3]. The turbulence leads to vibration of the soft tissues in the collapsible part of the upper airway. This extends from the choanae to the epiglottis and involves the soft palate, the uvula, the tonsils, the tonsillar pillars, the tongue base and the muscles of the pharynx [4].

In normal individuals upper airway narrowing increases the resistance to airflow at sleep onset. The nose accounts half of the total airway resistance to airflow and a semi-blocked nose requires increased inspiratory effort; this lowers intrapharyngeal pressures and tends to suck the pharyngeal walls together causing increased snoring [5]. Many patients have a worsening of their snoring when they suffer from an upper respiratory tract infection or an increasing in nasal resistance which may aggravate snoring by increasing the negative intrapharyngeal pressure leading to inspiration flow limitation and trembling of the upper airway walls [6].

Patients with sleep apnea have narrowing in the oropharynx, usually at the level of the uvula-soft palate complex or the base of the tongue [7] [8]. Less frequently, tonsillar hypertrophy, pharyngeal tumors, or other disorders may cause obstructive sleep apnea (OSA) [9]-[14]. Several clinical symptoms such as snoring, apnea during sleep, and other disturbances may possibly present [15].

Different modalities, such as polysomnography, endoscopy, are used in the diagnosis and evaluation of OSA [16]-[18]. Diagnosis may be difficult and more complicated in choosing the best surgical procedure in each case. Computed tomography (CT) is a noninvasive technique that allows a detailed assessment of the entire upper airway [19]-[21]. CT scanning significantly improves soft tissue contrast, leads surgical interventions toward the abnormal anatomic sites and allows for precise measurements of cross-sectional areas at different levels [22]. Studies utilizing CT scanning have been able to show correlations between anatomic changes and step up of obstruction parameters, giving an accurate measurement of upper airway area [23].

Sleep-disordered breathing is a series of disorders ranging from primary snoring to severe OSA [24]. It is thought to be due to varying combinations of anatomical and neuromuscular factors resulting in airway obstruction. Different ethnic groups have significant differences in craniofacial and soft tissue features. These ethnic differences in craniofacial morphology greatly affect airway dimensions as Caucasians, Afro-Americans Asian populations [25] [26]. Since craniofacial features differ among ethnic populations, specific characteristics for each population might suggest the risk for snoring in concerned ethnic population and require further diagnostic evaluation. The patients with snoring should be evaluated for nasal airway obstruction. In this study, we characterize the UA that has been evaluated subjectively as nasal obstruction using a quantify method for the corresponding anatomic upper air way parameters in patients with snoring using CT so as to acquire better results in distinguishing healthy controls from snoring patients.

\section{Materials and Methods}

\subsection{Sample and Technique}

Two hundred patients undergoing CT scanning for head and neck were included in the study. 147 (73.5\%) were males and 53 (26.5\%) were females. The sample was divided into two groups (snoring group [ $\mathrm{n}=127]$ and non-snoring group [ $n=73]$ ) (mean age: $44.8 \pm 15.9$ years and $26.2 \pm 7.0$ ). The CT scans of patients without snoring or any sleep related symptoms or changes affected the upper air way tract were evaluated as controls and were used for comparison with snoring group. All participants were non traumatic. In the present study the Saudi population in the sample including 174 patients and the rest were from other Asian populations. Verbal consent was firstly obtained from all potential participants. The aims, benefits of the present study were explained to all participants in details. As the majority of individuals who snore are unaware of their snoring, questions about snoring were answered by the bed partner or relatives and not by the snorer themselves and those with conditions that may in any way, alter the findings of the current study were excluded. MDCT scanner was (Toshiba Aquilion (TSX101A) 16 slice, (Jizan General Hospital, KSA)). The study span during the period from 2014-2015. 
The examinations were performed with all patients in the supine position with their heads and neck in a neutral position, lateral scout view was taken first to determine the level of the scans, Scanning was done from the lower portion of the upper cervical spine to the upper facial orbit. The conditions of scanning were $120 \mathrm{kVp}, 300$ $\mathrm{mA}$ with slice thickness of $1,1.5$ and $2 \mathrm{~mm}$. pixel size $512 \times 512$. Measurements were done on the lateral scout view and sagittal views, using special computer soft ware (RadiAnt DICOM viewer $32 \mathrm{BIT}$ ).

Neck circumference (NC) at the level of coric thyroid membrane, ages and seven standard bony and soft-tissue measurements to show changes in snoring patients were obtained.

\subsubsection{Identifying Variables}

a- $\quad$ Soft palate length (PNS-U) that is the distance between posterior nasal spine and the uvula,

b- Maximum thickness of soft palate (SP max),

c- $\quad$ Upper airway length (UAL) is vertical distance from the hard palate to the hyoid bone,

d- Retroplatal width (RP) behind the soft palate,

e- $\quad$ Retroglosal width (RS) behind the tongue,

$\mathrm{f}-\quad \mathrm{MP}-\mathrm{H}$ is the distance between mandibular plane and hyoid bone,

g- ANS-PNS is the linear distance between anterior nasal spine (ANS), and posterior nasal spine (PNS).

\subsubsection{Identifying Reference Points}

h- Anterior Nasal Spine (ANS) — the most anterior point on the maxilla at the nasal base,

i- $\quad$ Posterior Nasal Spine (PNS) - the tip of the posterior nasal spine of the palatine bone, at the junction of the soft and hard palate.

\subsection{Data Analyses}

Data were analyzed using Statistical Package of Social Sciences (SPSS) (Inc., Chicago, Illinois version 16). The data obtained were analyzed statistically by computing descriptive statistics: Mean, \pm SD values and percentages. Paired t-test was used for testing the differences between the formulae results. The difference at value of $\mathrm{P}<$ 0.01 will be considered significant.

\section{Results}

The following tables presented the data obtained from snoring and non snoring patients. Mean age of the snoring males was $42.6 \pm 14.61$ years and the females was $53.2 \pm 18.25$ years.

\section{Discussion}

The present study included both genders. The prevalence of snoring was found to be 127 patients including 100 males (78.7\%), their ages were $42.6 \pm 14.61$ and 27 females (21.3\%), and their ages were $53.2 \pm 18.25$ age ranged between 15 and $>75$ years (Figure 1). Comparing with previous studies done for snoring; men and

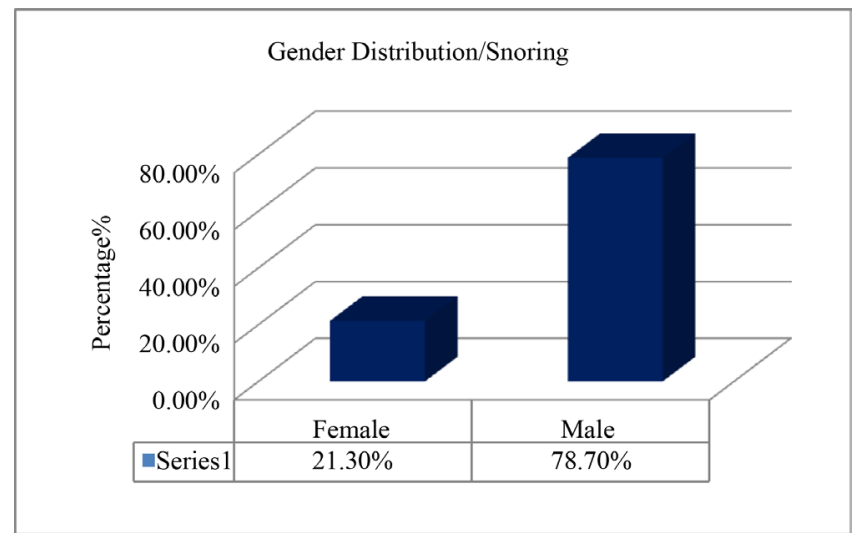

Figure 1. Classification of snoring group according to gender presented in percentages $\%$. 
women showed an increase of snoring in mid-life [27]-[29]. In other study of patients between 30 and 60 years of age, the highest prevalence were found among men between 50 and 60 years. Fifty three percent of men and $31 \%$ of women in this age group reported snoring [30]. Large population based studies have shown an increasing trend in prevalence of snoring up to the age group of 60 - 69 years in Finland [31] and up to 60 - 70 years in Spain [32]. Other studies have reported higher prevalence among middle-aged populations: $44 \%$ in men and $28 \%$ in women in the USA and $28 \%$ - 44\% and 6\% - 19\% in Finland, respectively [27] [30] [31]. Men have 2- to 3fold greater risk of snoring than women, but mechanisms underlying this difference are not clear. Results from a recent study suggest that increased collapsibility in the pharyngeal airway in men is based on anatomical differences [33].

Table 1 shows independent samples t-test for equality of means between the snoring and non snoring groups studied for age and different anatomical areas differences. Significant difference between the ages of snoring patients and non snoring group at $\mathrm{p} \leq 0.000$ was detected. The difference between the neck circumference (NC) was found to be significantly differ and greater in snoring patients than non-snoring at $p \leq 0.000$. The importance of considering the measurement of NC because it is was established that having a neck circumference (NC) of $40 \mathrm{~cm}$ or more is one of the most significant risk factor for the development of Obstructive Sleep Apnea Syndrome (OSAS) and it is a cutoff point as a risk factor for OSAS [34]. Our sample have less measurement and not reach the cutoff point of obstruction diagnosis, but it differ from non-snoring; it means the measurements increased by $43 \mathrm{~mm}$ from $109.4 \mathrm{~mm}$ for patients measurements ranged from 84.5 - $126 \mathrm{~mm}$, may consider as snoring complain but not broaden to be diagnosed as obstruction sleep apnea. We justify this findings is that to be anatomical variations between different studied ethnic groups [26] [33]. Despite the clear association between snoring underlying causes and obesity, the mechanisms behind this relationship is not yet fully understood. Particular patterns of fat distribution may be specifically relevant and underlie the pathophysiological

Table 1. Independent samples T-test for equality of means between the snoring and non snoring groups studied for age and different anatomical areas.

\begin{tabular}{|c|c|c|c|c|c|c|}
\hline & Group & $\mathrm{N}$ & Mean \pm SD & MAX & MIN & P-value \\
\hline \multirow{2}{*}{ AGE } & Snoring & 127 & $44.8 \pm 15.9$ & 85 & 18 & \multirow{2}{*}{$0.000^{* *}$} \\
\hline & Non snoring & 73 & $26.2 \pm 7.0$ & 47 & 15 & \\
\hline \multirow{2}{*}{$\mathrm{NC}$} & Snoring & 127 & $151.5 \pm 97.1$ & 1222 & 104 & \multirow{2}{*}{$0.000^{* *}$} \\
\hline & Non snoring & 73 & $109.4 \pm 10.6$ & 126 & 84.5 & \\
\hline \multirow{2}{*}{ MP-H } & Snoring & 127 & $14.4 \pm 13.3$ & 153 & 0.0 & \multirow{2}{*}{0.059} \\
\hline & Non snoring & 73 & $11.3 \pm 5.1$ & 31.8 & 4.10 & \\
\hline \multirow{2}{*}{ ANS-PNS } & Snoring & 127 & $54.2 \pm 32.8$ & 418 & 38 & \multirow{2}{*}{0.170} \\
\hline & Non snoring & 73 & $48.9 \pm 4.5$ & 62.6 & 41.7 & \\
\hline \multirow{2}{*}{ Rs } & Snoring & 127 & $14.0 \pm 3.7$ & 25 & 4.3 & \multirow{2}{*}{1.00} \\
\hline & Non snoring & 73 & $13.1 \pm 3.2$ & 22.3 & 7.5 & \\
\hline \multirow{2}{*}{$\mathrm{Rp}$} & Snoring & 127 & $6.0 \pm 5.0$ & 57 & 0.0 & \multirow{2}{*}{$0.001^{* *}$} \\
\hline & Non snoring & 73 & $9.3 \pm 8.2$ & 58 & 3.10 & \\
\hline \multirow{2}{*}{ UAL } & Snoring & 127 & $60.7 \pm 7.7$ & 80 & 45 & \multirow{2}{*}{$0.000^{* *}$} \\
\hline & Non snoring & 73 & $55.1 \pm 6.8$ & 72.4 & 39.9 & \\
\hline \multirow{2}{*}{ SP-MAX } & Snoring & 127 & $11.8 \pm 1.8$ & 18.2 & 5.8 & \multirow{2}{*}{$0.000^{* *}$} \\
\hline & Non snoring & 73 & $8.6 \pm 1.5$ & 11.8 & 5.3 & \\
\hline \multirow{2}{*}{ PNS-U } & Snoring & 127 & $41.3 \pm 31.9$ & 39.4 & 29 & \multirow{2}{*}{0.084} \\
\hline & Non snoring & 73 & $34.7 \pm 5.2$ & 49.7 & 23.7 & \\
\hline
\end{tabular}

\footnotetext{
${ }^{* *}$ Significance at level 0.01 .
} 
mechanisms. Neck fat deposition (neck circumference), have been specifically related to snoring [34] [35]. Obesity has also been clearly shown to be linked to sleep disturbance breathing. It seems that this is in part a proxy marker for neck circumference [36]. Therefore weight particularly is coincident with a presence of snoring.

The linear distance between mandibular plane and hyoid bone $(\mathrm{Mp}-\mathrm{H})$ was found to be greater and differ between the two groups. In snoring patients, the hyoid bone was found to be more inferiorly placed. The justification of the presence of snoring in such patients is that the lower position of the hyoid increase the mandibular consignment because of the requirement of extra energy to elevate the tongue; this, worsen apnea by resulting in the open-mouth posture during sleep concluded with snoring, this was similar to the finding mentioned in previous study [37], similarly Wong et al. found that the hyoid bone was located more posteriorly in Chinese snoring subjects when compared with Malays and Indians [38] and our study population were Saudi and other Asian populations. Retroplatal width (RP) was found to be smaller in snoring patients and differed significantly at $\mathrm{p} \leq$ 0.001. Upper airway length (UAL) which was measured as the vertical distance from hard palate to the hyoid bone differed significantly at $\mathrm{p} \leq 0.000$. When compared to snoring group, length of soft palate (PNS-U) was found to be longer in snoring than in non-snoring group but the difference is not significant $(\mathrm{P}<0.084)$. Adverse results were found in a study done by Abhishek Dubey [39].

The maximum thickness of the soft palate (SP max) differs significantly at $\mathrm{p} \leq 0.000$ between the two groups. The snoring patients in another similar study in different population showed significantly longer soft palate, which occupied more space in the oropharyngeal area. Studies had indicated that continuous vibration of the soft palate during snoring leads to continuous trauma and causes mucosal edema, further reducing upper airway patency [40]. The increased muscular stiffness of the soft palate suggests that its tissues undergo morphological and functional changes, supported by the findings of the uvular and soft palate muscles in snoring [40]. The changes thought to be due to varying combinations of anatomical and neuromuscular factors resulting in airway changes [26]. In our sample, there is no pathological findings or underlying cause for obstruction were detected except the changing in the measurements. Predictive factors in upper airway anatomy or detected variation that explaining the progression of snoring were not found, another similarly study done by Pendlebury et al.,1997 mentioned similar findings [41].

However, this mechanism depends on the morphology orofacial musculature. Many other studies have also found that the interrelationship of craniofacial morphology and muscle function of the upper airway is important in the understanding pathogenesis behind snoring [42]. Different ethnic groups have significant differences in craniofacial and soft tissue features. These ethnic differences in craniofacial morphology greatly affect airway dimensions [39]. These differences were due to ethnicity changes. We suppose that the difference between the two groups is that they are of different ethnicity.

Mean and standard deviation, t-test for equality of means of the measured anatomical areas for snoring patients classified according to gender were studied and the measurements were presented in (Table 2). No significant difference was detected in the evaluated anatomical structures between genders except the UAL; the men have greater measurements than females in the studied population. Results from a recent study suggest that increased collapsibility in the pharyngeal airway in men is based on anatomical differences between genders as mentioned by Malhotra et al. (2002a) [33]. Age classes have no impact on the measured anatomical areas for snoring patients this was presented in (Table 3). Studies showed that the reasons for differences in prevalence of snoring with age are poorly understood as mentioned in previous studies [43].

Several imaging methods had evaluated and measured the upper air way tract [44]. Two-dimensional (2D) lateral cephalograms have traditionally served as the radiographic standard for airway assessment in patients with upper respiratory tract problems. Although lateral cephalometric measurements are useful for analyzing airway size in the sagittal plane, they do not accurately depict the 3-dimensional (3D) airway anatomy. In addition, the correlation of commonly used linear and angular measurements obtained from lateral cephalograms with the severity of disease, has not been documented in published studies [45]-[47]. Finally, although the most physiologically relevant information is obtained from axial images, perpendicular to the direction of airflow, the axial plane is not visualized on lateral cephalograms [48].

In contrast, an accurate 3D image of the airway can be obtained using computed tomographic (CT) data in the coronal, axial, and sagittal planes [49]. Although multiple reports have been published on the use of CT imaging for assessment of the upper airway, few data are available on the reliability of this technique [50] [51].

The advantage of our usage of the based technique and imaging methods in the current study is that with MDCT, thin-section images of the entire central airways was obtained in only a few seconds, creating an isotropic data set in which the resolution is excellent [52]. MDCT technique provides higher spatial resolution, 
Table 2. Mean and standard deviation, T-test for equality of means of the measured anatomical areas for snoring patients classified according to gender.

\begin{tabular}{|c|c|c|c|c|}
\hline & GENDER & $\mathrm{N}$ & Mean \pm S.D & P-value \\
\hline \multirow{2}{*}{ NC } & Male & 100 & $155.4 \pm 108.99$ & \multirow{2}{*}{0.390} \\
\hline & Female & 27 & $137.2 \pm 14.65$ & \\
\hline \multirow{2}{*}{ MP-H } & Male & 100 & $13.5 \pm 4.87$ & \multirow{2}{*}{0.158} \\
\hline & Female & 27 & $17.6 \pm 27.52$ & \\
\hline \multirow{2}{*}{ ANS-PNS } & Male & 100 & $51.8 \pm 4.73$ & \multirow{2}{*}{0.110} \\
\hline & Female & 27 & $63.2 \pm 71.03$ & \\
\hline \multirow{2}{*}{ Rs } & Male & 100 & $14.0 \pm 3.89$ & \multirow{2}{*}{0.979} \\
\hline & Female & 27 & $14.0 \pm 3.32$ & \\
\hline \multirow[b]{2}{*}{$\mathrm{Rp}$} & Male & 100 & $6.2 \pm 5.57$ & \multirow[b]{2}{*}{0.209} \\
\hline & Female & 27 & $4.9 \pm 1.77$ & \\
\hline \multirow{2}{*}{ UAL } & Male & 100 & $62.3 \pm 7.34$ & \multirow{2}{*}{$0.000^{* *}$} \\
\hline & Female & 27 & $54.8 \pm 6.64$ & \\
\hline \multirow{2}{*}{ SP-MAX } & Male & 100 & $11.9 \pm 1.77$ & \multirow{2}{*}{0.071} \\
\hline & Female & 27 & $11.2 \pm 2.25$ & \\
\hline \multirow{2}{*}{ PNS-U } & Male & 100 & $42.6 \pm 35.85$ & \multirow{2}{*}{0.373} \\
\hline & Female & 27 & $36.4 \pm 4.39$ & \\
\hline
\end{tabular}

\footnotetext{
${ }^{* *}$ Significance at level 0.01 .
}

faster speed, greater anatomic coverage, and higher quality multiplanar reformation and 3-D reconstruction images. Multiplanar and 3-D reconstruction images help to overcome the limitations of axial images by providing a more anatomically meaningful display of complex structures of the airways [53] [54]. These images have been shown to enhance the detection of airway stenoses if present and to aid the assessment of the craniocaudal extent of the stenosis, and to clarify complex airway abnormalities [55]. They have also been shown to improve diagnostic confidence of interpretation, measurements and enhance pre-procedural planning for bronchoscopy and surgery [53].

Although multiplanar and 3-D reconstruction images do not actually create new data, they provide an alternative method of viewing CT data that is often more visually accessible and anatomically meaningful.

The progress in CT technology allowed us to obtain high resolution 1, 2-mm-thick sections. The setting of computer window and zoom factor ensured high accuracy in measurements. We believe that the measurements of the upper air way tract by modern CT technique can be used as a guide for the evaluation of norms, diseases and their severity before and after surgery. Sagittal reconstruction can demonstrate the narrowing at the level of the uvulopalatinal complex and at the base of the tongue. The CT reconstruction can be important when there are difficulties in deciding which the procedure of choice is. Uvulopalatopharyngoplasty should be the choice when there is only uvulopalatinal narrowing [44]. However the CT reconstruction is a nonaggressive technique for demonstrating the location of the pharyngeal narrowing if present.

\section{Conclusions}

Results showed that the NC, UAL, and SP max were significantly higher in snoring group; however RP was also found to be significantly lower. Inferior positioning of hyoid bone gives longer measurement for MP-H. In snoring group UAL was found to be significantly different at $\mathrm{p} \leq 0.000$ between the two genders. All the measured variables showed no significant differences in respect to age. UA CT quantitative features play an important role in the characterization of the anatomy and are compared between snoring patients and non-snoring 
F. A. El R. M. Alamin, C. E. Ayad

Table 3. Mean and standard deviation, T-test for equality of means of the measured anatomical areas for snoring patients classified according to age classes.

\begin{tabular}{|c|c|c|c|c|c|c|}
\hline \multicolumn{6}{|c|}{ Descriptive } & \multirow{2}{*}{$\begin{array}{c}\text { ANOVA } \\
\text { P-value }\end{array}$} \\
\hline & & $\mathrm{N}$ & Mean \pm S.D & Minimum & Maximum & \\
\hline \multirow{6}{*}{ Rs } & $15-30$ & 20 & $14.2 \pm 4.27$ & 7.60 & 23.40 & \multirow{6}{*}{0.072} \\
\hline & $31-45$ & 57 & $14.0 \pm 3.63$ & 6.50 & 21.40 & \\
\hline & $46-60$ & 30 & $12.8 \pm 3.46$ & 4.30 & 19.30 & \\
\hline & $61-75$ & 12 & $16.5 \pm 4.21$ & 12.00 & 25.00 & \\
\hline & $>75$ & 8 & $14.4 \pm 2.39$ & 10.80 & 17.90 & \\
\hline & Total & 127 & $14.0 \pm 3.77$ & 4.30 & 25.00 & \\
\hline \multirow{6}{*}{$\mathrm{Rp}$} & $15-30$ & 20 & $6.5 \pm 2.45$ & 2.20 & 11.40 & \multirow{6}{*}{0.627} \\
\hline & $31-45$ & 57 & $6.4 \pm 7.02$ & 1.50 & 57.00 & \\
\hline & $46-60$ & 30 & $5.2 \pm 2.52$ & 0.00 & 11.50 & \\
\hline & $61-75$ & 12 & $6.2 \pm 2.41$ & 2.30 & 10.00 & \\
\hline & $>75$ & 8 & $3.9 \pm .66$ & 3.00 & 4.90 & \\
\hline & Total & 127 & $6.0 \pm 5.03$ & 0.00 & 57.00 & \\
\hline \multirow{6}{*}{ UAL } & $15-30$ & 20 & $58.1 \pm 6.64$ & 46.30 & 67.70 & \multirow{6}{*}{0.075} \\
\hline & $31-45$ & 57 & $61.1 \pm 8.24$ & 45.00 & 80.80 & \\
\hline & $46-60$ & 30 & $63.2 \pm 7.3$ & 51.30 & 80.40 & \\
\hline & $61-75$ & 12 & $56.9 \pm 7.91$ & 47.20 & 71.20 & \\
\hline & $>75$ & 8 & $60.3 \pm 6.12$ & 46.30 & 66.90 & \\
\hline & Total & 127 & $60.7 \pm 7.79$ & 45.00 & 80.80 & \\
\hline \multirow{6}{*}{ SP-MAX } & $15-30$ & 20 & $11.1 \pm 2.35$ & 5.80 & 16.20 & \multirow{6}{*}{0.234} \\
\hline & $31-45$ & 57 & $12.1 \pm 1.53$ & 7.70 & 15.80 & \\
\hline & $46-60$ & 30 & $11.7 \pm 2.04$ & 7.40 & 15.70 & \\
\hline & $61-75$ & 12 & $11.3 \pm 2.45$ & 8.60 & 18.20 & \\
\hline & $>75$ & 8 & $12.2 \pm 1.23$ & 10.80 & 14.70 & \\
\hline & Total & 127 & $11.8 \pm 1.89$ & 5.80 & 18.20 & \\
\hline \multirow{6}{*}{ PNS-U } & $15-30$ & 20 & $38.0 \pm 4.74$ & 31.90 & 47.00 & \multirow{6}{*}{0.908} \\
\hline & $31-45$ & 57 & $44.4 \pm 47.39$ & 29.10 & 394.00 & \\
\hline & $46-60$ & 30 & $39.2 \pm 4.84$ & 31.50 & 50.00 & \\
\hline & $61-75$ & 12 & $38.0 \pm 6.65$ & 29.40 & 52.50 & \\
\hline & $>75$ & 8 & $39.7 \pm 4.99$ & 30.50 & 46.00 & \\
\hline & Total & 127 & $41.3 \pm 31.94$ & 29.10 & 394.00 & \\
\hline \multirow{6}{*}{$\mathrm{NC}$} & $15-30$ & 20 & $137.9 \pm 15.54$ & 112.00 & 177.40 & \multirow{6}{*}{0.916} \\
\hline & $31-45$ & 57 & $159.7 \pm 143.87$ & 118.70 & 1222.00 & \\
\hline & $46-60$ & 30 & $150.8 \pm 18.49$ & 117.70 & 184.60 & \\
\hline & $61-75$ & 12 & $140.5 \pm 21.34$ & 104.30 & 174.50 & \\
\hline & $>75$ & 8 & $146.7 \pm 11.22$ & 130.50 & 159.10 & \\
\hline & Total & 127 & $151.5 \pm 97.13$ & 104.30 & 1222.00 & \\
\hline
\end{tabular}




\begin{tabular}{|c|c|c|c|c|c|c|}
\hline Continued & & & & & & \\
\hline \multirow{6}{*}{ MP-H } & $15-30$ & 20 & $12.5 \pm 4.27$ & 6.50 & 22.80 & \multirow{6}{*}{0.446} \\
\hline & $31-45$ & 57 & $13.0 \pm 5.09$ & 0.00 & 24.30 & \\
\hline & $46-60$ & 30 & $18.3 \pm 25.97$ & 5.70 & 153.00 & \\
\hline & $61-75$ & 12 & $13.4 \pm 4.59$ & 6.60 & 19.60 & \\
\hline & $>75$ & 8 & $15.3 \pm 4.48$ & 8.10 & 22.20 & \\
\hline & Total & 127 & $14.4 \pm 13.33$ & 0.00 & 153.00 & \\
\hline \multirow{6}{*}{ ANS-PNS } & $15-30$ & 20 & $52.5 \pm 5.42$ & 43.80 & 61.70 & \multirow{6}{*}{0.079} \\
\hline & $31-45$ & 57 & $51.2 \pm 5.25$ & 38.00 & 64.20 & \\
\hline & $46-60$ & 30 & $51.6 \pm 3.93$ & 42.60 & 61.60 & \\
\hline & $61-75$ & 12 & $80.2 \pm 106.40$ & 44.00 & 418.00 & \\
\hline & $>75$ & 8 & $51.1 \pm 3.87$ & 45.80 & 58.70 & \\
\hline & Total & 127 & $54.2 \pm 32.87$ & 38.00 & 418.00 & \\
\hline
\end{tabular}

subjects adding information about the ethnicity and gender related difference. Further investigation was required using large sample of snores and non-snores concerning only Saudi population in order to establish norms for their measurements so as to predict early changes in UA in cases of sleep-disordered breathing diagnosing series of disorders ranging from primary snoring to severe OSA.

From this point of view, however, the axial images provide a more comprehensive review of the entirety of the thoracic structures and also serve as an important point of reference for optimal interpretation of multiplanar and 3-D images. Thus, we recommended that the radiologist should review the traditional axial images in addition to the alternative display images (multiplanar and 3-D reconstruction images) when interpreting a CT study of the upper air way tract, in addition to evaluate the lower respiratory tract and related thoracic structures. Despite the study done on the selected anatomical structures with age and gender, additional studies, with larger numbers of patients, are required to document the benefits of this technology using axial and multiplanar 3D images to characterize the upper and lower air way tract.

\section{References}

[1] Kane, J.W. and Sternhe, M.M. (1979) Life Science Physics. 2nd Edition, John Wiley \& Sons Inc., New York, Vol I.

[2] Dalmasso, F. and Prota, R. (1996) Snoring: Analysis, Measurement, Clinical Implications and Applications. European Respiratory Journal, 9, 146-159. http://dx.doi.org/10.1183/09031936.96.09010146

[3] Stradling, R. (1995) Obstructive Sleep Apnoea: Definitions, Epidemiology, and Natural History. Thorax, 50, $683-689$. http://dx.doi.org/10.1136/thx.50.6.683

[4] Von Lunteran, E. and Stroll, K.P. (1986) The Muscles of the Upper Airways. Clinics in Chest Medicine, 7, 171-188.

[5] Olsen, K.D. (1987) The Nose and Its Impact on Snoring and Obstructive Sleep Apnoea. In: Fairbanks, D.N.F., Oita, F., Ikematsu, T. and Simmons, F.B., Eds., Snoring and Obstructive Sleep Apnoea, Raven Press, New York, 1-18.

[6] Hoffstein, V. (1996) Snoring. Chest, 109, 201-222. http://dx.doi.org/10.1378/chest.109.1.201

[7] Bradley, T.D., Brown, L.G. and Grossman, R.F. (1986) Pharyngeal Size in Snorers, Non-Snorers and Patients with Obstructive Sleep Apnea. New England Journal of Medicine, 315, 1327-1331. http://dx.doi.org/10.1056/NEJM198611203152105

[8] Grumley, R.L., Stein, M., Gamsu, G., Golden, J. and Dermon, S. (1987) Determination of Obstructive Site in Obstructive Sleep Apnea. Laryngoscope, 97, 301-308.

[9] Orr, W.C. and Martin, R.J. (1981) Obstructive Sleep Apnea Associated with Tonsillar Hypertrophy in Adults. Archives of Internal Medicine, 141, 990-992. http://dx.doi.org/10.1001/archinte.1981.00340080030011

[10] Mangot, D., Orr, W.C. and Smith, R.O. (1977) Sleep Apnea, Hyper Somnolence and Upper Airway Obstruction Secondary to Adenotonsillar Enlargement. Archives of Otolaryngology, 103, 383-386. http://dx.doi.org/10.1001/archotol.1977.00780240041003

[11] Guilleminault, C., Tikian, A. and Dement, W.C. (1986) The Sleep Apnea Syndromes. Annual Review of Medicine, 27, 465-484. http://dx.doi.org/10.1146/annurev.me.27.020176.002341 
[12] Sackner, M., Landa, J., Forrest, T. and Greeneltch, D. (1975) Periodic Sleep Apnea: Chronic Sleep Deprivation Related to Intermittent Upper Airway Obstruction and Central Nervous System Disturbance. Chest, 67, 164-171. http://dx.doi.org/10.1378/chest.67.2.164

[13] Imes, N.R., Orr, W.C., Smith, R.O. and Rogers, R.M. (1977) Retrognatia and Sleep Apnea. JAMA, 237, $1596-1587$. http://dx.doi.org/10.1001/jama.1977.03270420064019

[14] Vallgo, A. and Atroy, G. (1965) Hypoventilation in Acquired Micrognathia. Archives of Internal Medicine, 115, 307310. http://dx.doi.org/10.1001/archinte.1965.03860150051009

[15] Remmers, J.E., DeGroot, W.J., Sauerland, E.K. and Anch, A.M. (1978) Pathogenesis of Upper Airway Occlusion during Sleep. Journal of Applied Physiology, 44, 931-938.

[16] Guilleminault, C., Riley, R. and Powell, N. (1987) Sleep Apnea in Abnormal Cephalometric Measurements. Chest, 86, 783-794.

[17] Walsh, J.K. and Vatsantonis, G.P. (1984) Somno Fluoroscopy as a Predictor of UPPP Efficacy. Sleep Research, 13, 21.

[18] Rivlin, J., Hoffstein, V., Kolbfleisch, J., McNicoles, W.T., Zamel, N. and Bryan, A.C. (1984) Upper Airway Morphology in Patients with Idiopathic Obstructive Sleep Apnea. American Review of Respiratory Disease, 129, 355-360.

[19] Haponic, E.F., Smith, P.L., Bohlman, M.E., Allen, R.P., Goldman, S.M. and Bleecker, E.R. (1983) Computerized Tomography in Obstructive Sleep Apnea. American Review of Respiratory Disease, 127, 221-226.

[20] Bohlman, M.E., Haponik, E.F., Smith, P.L., Allen, R.P. and Bleecker, E.R. (1983) CT Demonstration of Pharyngeal Narrowing in Adult Obstructive Sleep Apnea. American Journal of Roentgenology, 140, 534-548. http://dx.doi.org/10.2214/ajr.140.3.543

[21] Sutatt, P.M., Dee, P., Atkinson, R.L., Armstrong, P. and Wilhoit, S.C. (1983) Fluoroscopic and Computed Tomography Features in the Pharyngeal Airway in Obstructive Sleep Apnea. American Review of Respiratory Disease, 127, 487-492. http://dx.doi.org/10.1164/arrd.1983.127.4.487

[22] Lefebvre, E. and Moreau, R. (2010) Snoring: Causes, Diagnosis and Treatment. Nova Science Publishers, Inc., New York.

[23] Songu, M. and Adibelli, Z.H. (2010) Diagnostic Imaging Studies in Sleep-Disordered Breathing. In: Lefebvre, E. and Moreau, R., Eds., Snoring: Causes, Diagnosis and Treatment, Chap. 1, Nova Science Publishers, Inc., New York, $10-$ 12.

[24] Berry, R.B., Budhiraja, R., Gottlieb, D.J., Gozal, D., Iber, C. and Kapur, V.K. (2012) Rules for Scoring Respiratory Events in Sleep: Update of the 2007 AASM Manual for the Scoring of Sleep and Associated Events. Deliberations of the Sleep Apnea Definitions Task Force of the American Academy of Sleep Medicine. Journal of Clinical Sleep Medicine, 8, 597-619. http://dx.doi.org/10.5664/jcsm.2172

[25] Finkelstein, Y., Wolf, L., Nachmani, A., Lipowezky, U., Rub, M., Shemer, S., et al. (2014) Velopharyngeal Anatomy in Patients with Obstructive Sleep Apnea versus Normal Subjects. Journal of Oral and Maxillofacial Surgery, 72 , 1350-1372. http://dx.doi.org/10.1016/j.joms.2013.12.006

[26] Lee, R.W., Vasudavan, S., Hui, D.S., Prvan, T., Petocz, P. and Darendeliler, M.A. (2010) Differences in Craniofacial Structures and Obesity in Caucasian and Chinese Patients with Obstructive Sleep Apnea. Sleep, 33, 1075-1080.

[27] Martikainen, K., Partinen, M., Urponen, H., Vuori, I., Laippala, P. and Hasan, J. (1994) Natural Evolution of Snoring: A 5-Year Follow-Up Study. Acta Neurologica Scandinavica, 90, 437-442. http://dx.doi.org/10.1111/j.1600-0404.1994.tb02754.X

[28] Honsberg, A.E., Dodge, R.R., Cline, M.G. and Quan, S.F. (1995) Incidence and Remission of Habitual Snoring over a 5- to 6-Year Period. Chest, 108, 604-609. http://dx.doi.org/10.1378/chest.108.3.604

[29] Lindberg, E., Taube, A., Janson, C., Gislason, T., Svärdsudd, K. and Boman, G.A. (1998) 10-Year Follow-Up of Snoring in Men. Chest, 114, 1048-1055. http://dx.doi.org/10.1378/chest.114.4.1048

[30] Young, T., Palta, M., Dempsey, J., Skatrud, J., Weber, S. and Badr, S. (1993) The Occurrence of Sleep-Disordered Breathing among Middle-Aged Adults. The New England Journal of Medicine, 328, 1230-1235. http://dx.doi.org/10.1056/NEJM199304293281704

[31] Koskenvuo, M., Partinen, M. and Kaprio, J. (1985) Snoring and Disease. Annals of Clinical Research, 17, $247-251$.

[32] Durán, J., Esnaola, S., Rubio, R. and Iztueta, Á. (2001) Obstructive Sleep Apnea-Hypopnea and Related Clinical Features in a Population-Based Sample of Subjects Aged 30 to 70 Yr. American Journal of Respiratory and Critical Care Medicine, 163, 685-689. http://dx.doi.org/10.1164/ajrccm.163.3.2005065

[33] Malhotra, A., Huang, Y., Fogel, R.B., Pillar, G., Edwards, J.K., Kikinis, R., Loring, S.H. and White, D.P. (2002) The Male Predisposition to Pharyngeal Collapse. Importance of Airway Length. American Journal of Respiratory and Critical Care Medicine, 166, 1388-1395. http://dx.doi.org/10.1164/rccm.2112072

[34] Young, T., Peppard, P.E. and Gottlieb, D.J. (2002) Epidemiology of Obstructive Sleep Apnea. A Population Health Perspective. American Journal of Respiratory and Critical Care Medicine, 165, 1217-1239. 
http://dx.doi.org/10.1164/rccm.2109080

[35] Carmelli, D., Swan, G.E. and Bliwise, D.L. (2000) Relationship of 30-Year Changes in Obesity to Sleep-Disordered Breathing in the Western Collaborative Group Study. Obesity Research, 8, 632-637. http://dx.doi.org/10.1038/oby.2000.81

[36] Stradling, J. and Crosby, J. (1991) Predictors and Prevalence of Obstructive Sleep Apnoea and Snoring in 1001 Middle-Aged Men. Thorax, 46, 85-90. http://dx.doi.org/10.1136/thx.46.2.85

[37] Arya, D., Tripathi, A., Singh, S.V., Tripathi, S., Nagar, A. and Mishra, A. (2010) A Pilot Study to Evaluate Posttreatment Cephalometric Changes in Subjects with OSA. The Journal of Prosthetic Dentistry, 103, 170-177. http://dx.doi.org/10.1016/S0022-3913(10)60024-8

[38] Wong, M.L., Sandham, A., Ang, P.K., Wong, D.C., Tan, W.C. and Huggare, J. (2005) Craniofacial Morphology, Head Posture, and Nasal Respiratory Resistance in Obstructive Sleep Apnoea: An Inter-Ethnic Comparison. The European Journal of Orthodontics, 27, 91-97. http://dx.doi.org/10.1093/ejo/cjh077

[39] Dubey, A., Upadhyay, S., Mathur, S., Kant, S., Singh, B.P. and Makwana, R. (2015) Comparative Evaluation of Craniofacial Anthropometric Measurements in Indian Adult Patients with and without Obstructive Sleep Apnea: A Pilot Study. The Journal of Indian Prosthodontic Society, 15, 331-336.

[40] Veldi, M., Vasar, V., Vain, A. and Kull, M. (2004) Obstructive Sleep Apnea and Ageing Myotonometry Demonstrates Changes in the Soft Palate and Tongue While Awake. Pathophysiology, 11, 159-165.

[41] Pendlebury, S.T., Pépin, J.-L., Veale, D. and Lévy, P. (1997) Natural Evolution of Moderate Sleep Apnoea Syndrome: Significant Progression over a Mean of 17 Months. Thorax, 52, 872-878. http://dx.doi.org/10.1136/thx.52.10.872

[42] Chowdhuri, S., Pierchala, L., Aboubakr, S.E., Shkoukani, M. and Badr, M.S. (2008) Long-Term Facilitation of Genioglossus Activity Is Present in Normal Humans during NREM Sleep. Respiratory Physiology \& Neurobiology, 160, 65-75. http://dx.doi.org/10.1016/j.resp.2007.08.007

[43] Virkkula, P. (2003) Diagnosis of Sleep-Related Breathing Disorders: Esophageal Pressure Monitoring, Nasal Resistance and Postural Cephalometry. Academic Dissertation, with Permission of the Medical Faculty of the University of Helsinki, in the Auditorium of the Department of Otorhinolaryngology \& Head and Neck Surgery, Haartmaninkatu 4 E, Helsinki, Yliopistopaino, Helsinki.

[44] Abramson, Z.R., Susarla, S., Tagoni, J.R. and Kaban, L. (2010) Three-Dimensional Computed Tomographic Analysis of Airway Anatomy. Journal of Oral and Maxillofacial Surgery Home, 68, 363-371. http://dx.doi.org/10.1016/j.joms.2009.09.086

[45] Zucconi, M., Ferini-Strambi, L., Palazzi, S., et al. (1992) Habitual Snoring with and without Obstructive Sleep Apnoea: The Importance of Cephalometric Variables. Thorax, 47, 157-161. http://dx.doi.org/10.1136/thx.47.3.157

[46] Schafer, J., Sieron, J., Pirsig, W., Haase, S. and Lupberger, A. (1989) Radiocephalometric Findings and Duration of Snoring in Habitual Snoring and Obstructive Sleep Apnea Syndrome. Laryngo-Rhino-Otologie, 68, 163-168.

[47] Guilleminault, C., Riley, R. and Powell, N. (1984) Obstructive Sleep Apnea and Abnormal Cephalometric Measurements: Implications for Treatment. Chest, 86, 793-794. http://dx.doi.org/10.1378/chest.86.5.793

[48] Isono, S., Morrison, D.L., Launois, S.H., Feroah, T.R., Whitelaw, W.A. and Remmers, J.E. (1993) Static Mechanics of the Velopharynx of Patients with Obstructive Sleep Apnea. Journal of Applied Physiology, 75, 148-154.

[49] Schwab, R.J. (1998) Upper Airway Imaging. Clinics in Chest Medicine, 19, 33-54. http://dx.doi.org/10.1016/S0272-5231(05)70430-5

[50] Shigeta, Y., Enciso, R., Ogawa, T. and Clark, G.T. (2008) Changes in Three Dimensional Simulation Models of the Airway Which Are Due to Increases in Age or Body Mass Index. Studies in Health Technology and Informatics, 132, 460-462.

[51] Walsh, J.H., Leigh, M.S., Paduch, A., et al. (2008) Evaluation of Pharyngeal Shape and Size Using Anatomical Optical Coherence Tomography in Individuals with and without Obstructive Sleep Apnoea. Journal of Sleep Research, 17, 230-238. http://dx.doi.org/10.1111/j.1365-2869.2008.00647.x

[52] Choi, R.J. and Boiselle, P.M. (2001) Multidetector Helical Computed Tomography. In: Boiselle, P.M. and White, C.S., Eds., New Techniques in Thoracic Imaging, Marcel Dekker, New York, 71-90. http://dx.doi.org/10.1201/b14031-5

[53] Boiselle, P.M. and Ernst, A. (2002) Recent Advances in Central Airway Imaging. Chest, 121, 1651-1660. http://dx.doi.org/10.1378/chest.121.5.1651

[54] Boiselle, P.M., Reynolds, K.F. and Ernst, A. (2002) Multiplanar and Three-Dimensional Imaging of the Central Airways with Multidetector CT. American Journal of Roentgenology, 179, 301-308. http://dx.doi.org/10.2214/ajr.179.2.1790301

[55] Remy-Jardin, M., Remy, J., Artaud, D., Fribourg, M. and Duhamel, A. (1998) Volume Rendering of the Tracheobronchial Tree: Clinical Evaluation of Bronchographic Images. Radiology, 208, 761-770.

http://dx.doi.org/10.1148/radiology.208.3.9722857 


\section{Submit or recommend next manuscript to SCIRP and we will provide best service for you:}

Accepting pre-submission inquiries through Email, Facebook, LinkedIn, Twitter, etc.

A wide selection of journals (inclusive of 9 subjects, more than 200 journals)

Providing 24-hour high-quality service

User-friendly online submission system

Fair and swift peer-review system

Efficient typesetting and proofreading procedure

Display of the result of downloads and visits, as well as the number of cited articles

Maximum dissemination of your research work

Submit your manuscript at: http://papersubmission.scirp.org/ 